\title{
DISRUPTED QUADRICEPS TENDON POST KNEE ARTHROPLASTY: A CASE SERIES.
}

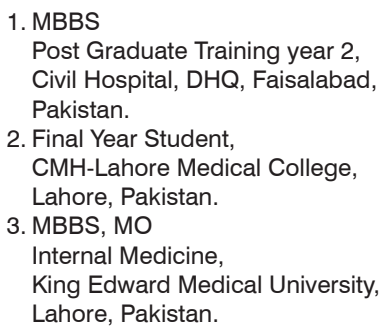

Correspondence Address: Dr. Muhammad Zaigham Maqsood Post Graduate Training year 2 . Civil Hospital, DHQ, Faisalabad, Pakistan.

zaighambajwa@yahoo.com

Article received on: 17/07/2019 Accepted for publication: 02/10/2019

\begin{abstract}
Muhammad Zaigham Maqsood ${ }^{1}$, Muhammad Arqam Maqsood ${ }^{2}$, Muhammad Haisum Maqsood $^{3}$
\end{abstract}
ABSTRACT... QTR (Quadriceps Tendon Rupture) occurs rarely after TKA (Total Knee Arthroplasty) but is a severe complication which has an association with morbidity and adverse outcomes. Rare literary evidence is available which deals with the complications. Delayed management may cause adverse outcomes so the focus is on the timely management of the disease; although, the diagnosis process is full of challenges because we expect weaker quadriceps after TKA as the surgical intervention violates quadriceps muscle. In case of postoperative trauma with the outcomes of weaker extensor weakness, a USG assessment is necessary to reduce the chances of prompt QTR performance after exclusion of the fracture. We have shared our experience about the treatment of four cases of QTR in the early postoperative time with focused efforts on prevention. We can reduce the chances of rupture with meticulous surgical approaches in the course of medial parapatellar method in order to preserve quadriceps integrity.

Key words: $\quad$ ASA (American Society of Anesthesiologist), Knee, KSS (Knee Society Score), Osteoarthritis, OKS (Oxford Knee Score), and Postoperative, QTR (Quadriceps Tendon Rupture), TKA (Total Knee Arthroplasty).

Article Citation: Maqsood MZ, Maqsood MA, Maqsood MH. Disrupted quadriceps tendon post knee arthroplasty: A case series. Professional Med J 2020; 27(2):442447. DOI: 10.29309/TPMJ/2020.27.2.3948

\section{INTRODUCTION}

Total Knee Arthroplasty (TKA) is a reliable treatment with suitable radiological and clinical outcomes for the patients of severe knee osteoarthritis. ${ }^{1,2}$ Balancing of tissues, precise bone cuts and appropriate placement of implant are necessary for better outcomes. In the course of arthrotomy, surgeons crucially require adequate exposure along with the maintenance of quadriceps tendon integrity in order to ensure good repair. In case of limited exposure, various surgical techniques like quadriceps snip, $\mathrm{V}-\mathrm{Y}$ quadricepsplasty and tibial tubercle osteotomy have been mentioned in the literature with better functional results after the surgical intervention of knee replacement. ${ }^{3-6}$

We know that postoperative onset of Quadriceps Tendon Rupture (QTR) is very rare complication after TKA which causes morbidity. ${ }^{7-11}$ According to Dobbs, there were $34 / 23,800$ QTR patients who also experienced TKA with poor outcomes and forty percent of repair rate postoperatively. ${ }^{10}$
This kind of QTR has been rarely reported in the literature.

This series puts emphasis on symptoms and signs pattern along with increasing the level of awareness about Post TKA onset of quadriceps rupture.

\section{Case Series}

Post TKA quadriceps rupture which was operated for knee osteoarthritis. All patients were assessed for ASA score, KSS, OKS and SF-36 before and after the operation. KSS is a combination of objective and subjective assessment which consists of functional and knee score. ${ }^{12}$ OKS is different and inversely related to the outcomes..$^{13}$ SF-36 has also mental and physical components. ${ }^{14}$

Surgical intervention involves a medial parapatellar method for knee having superior incision of quadriceps at musculotendinous interval and subsequent distally round patella 
and ends just medial to patella tendon.

Tibial and femoral bone cuts are performed with the help of jigs and posterior-stabilized prostheses are also utilized in all the patients. We perform patellar debridement without resurfacing and subsequently repair the tendon with No. 1 vicryl sutures which are followed by layered skin and subcutaneous tissues closure.

Patients can put weight on the walking frame in order to perform weight-bearing practice. After radiographic assessment, they can continue with physiotherapy. After fourth postoperative day, it is possible for the patients to climb stairs and the knee motion range is up to 90 . In this situation, they can be sent to home after discharge or sent to rehabilitation centre. Patients can be put on a walking stick in progressing ambulation. On outpatient's basis, one can continue with physiotherapy. Sutures are removed after two postoperative weeks and follow-up visits are planned on $2^{\text {nd }}, 6^{\text {th }}, 12^{\text {th }}$ and $24^{\text {th }}$ month after the surgery.

\section{Case-I:}

Was an old female of 72 years of age who had left knee osteoarthritis and underwent TKA. After two weeks postoperative review she was able to walk with the help of walking stick and postoperative motion range was from $5-120$. However, due to a pop sound, she visited the clinic as she experienced pain and she was also unable to extend the knee.

Radiographic assessment did not show any sign of fracture. There was distal quadriceps tendon architecture disruption at left patella superior pole with a small bony fragment on patella superior lateral aspect that measured about one centimetre. The gap between patellar bone and quadriceps tendon was about $1.1 \mathrm{~cm}$. A surgical repair was carried out on next day with a tear observed during intraoperative finding on left complete full thickness quadriceps tendon.

During follow-up visits the patients was able to walk and functional outcomes were also improved in the course of two years follow-up.

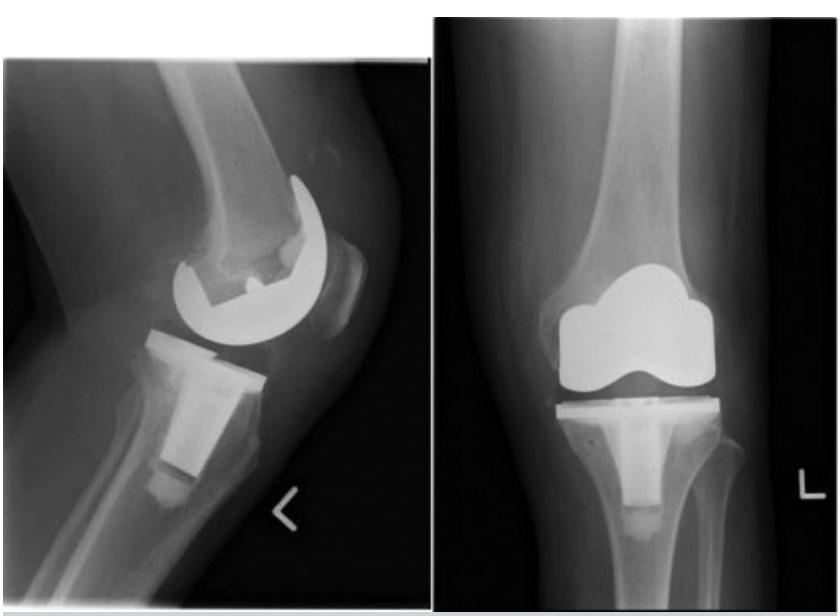

Figure-1: X-Ray Image of Left Knee After Pop Sound.

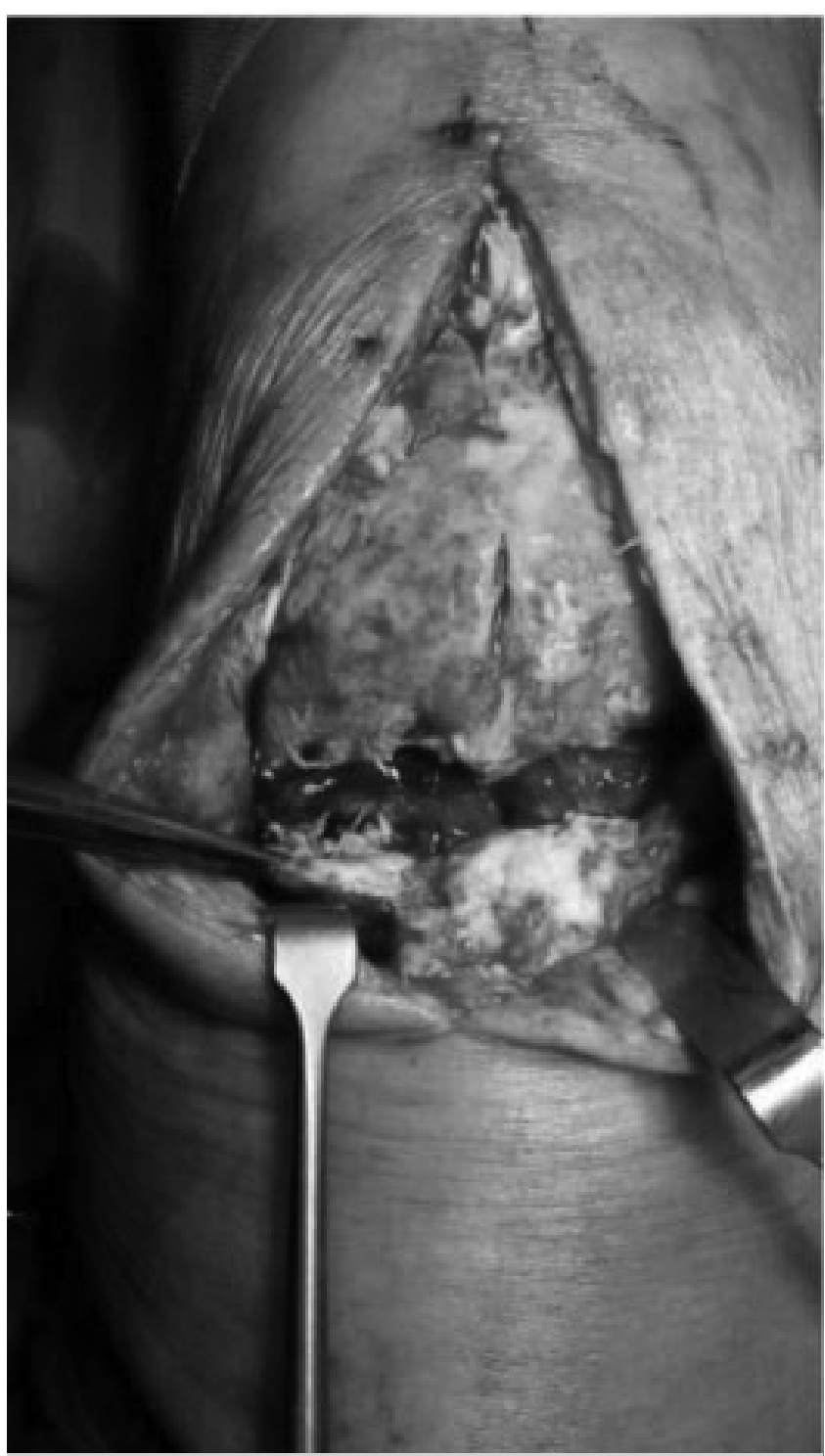

Figure-2: Intraoperative Finding. 
Case-II:

Was of 57 years of age and he experienced pain in the operated knee after slipping. One month postoperatively the physical assessment revealed left quadriceps muscles wasting with intact quadriceps without any palpable gap. Radiographic assessment did not reveal any signs of periprosthetic fracture. In order to strengthen the muscle, the patients underwent outpatient physiotherapy. Walking aid continued.

During the follow-up at 2 months postoperatively because of consistent pain. Patients received a repair of the quadriceps tendon. Quadriceps tendon tear was debrided and exposed with direct repair of eight sutures. Recovery rate was good and patients were able to walk without any aid but after six months the functional outcomes were still poor but later on, he lost his follow-up.

\section{Case-III:}

Was a 74 years old male who underwent right knee osteoarthritis TKA, Patient twisted and slipped his operated knee and launched a complaint about ambulating difficulty. There was no periprosthetic fracture as observed through radiographic assessment.

We advised the patients to continue with physiotherapy in order to strengthen the muscle. There was a palpable gap on quadriceps tendon which was repaired with the involvement of central and medical aspects with six sutures with an acceptable post repair strength.

After recovery patients still complained about walking easily and required a walking frame. Poor functional outcomes were reported postoperatively after six months. This patient also lost follow-up for two years.

\section{Case - IV}

Was of 73 years of age who underwent TKA for both of his knees first left knee and after that right knee. After ten days the patients complained about weakness and pain in the right knee as a result of fall. through radiographic assessment. We advised the patients to continue with physiotherapy in order to strengthen the muscle. There was a palpable gap on quadriceps tendon which was repaired. Patient reported persistent weakness and pain in the right knee. He also required walking frame support for the ambulation. We retracted the torn ends and filled the intervening gap by echogenic and hematoma fluid.

$X$ ray and ultrasound are shown in Figure 1, 3, 4 and 5 . Figure 2 shows the intraoperative findings.

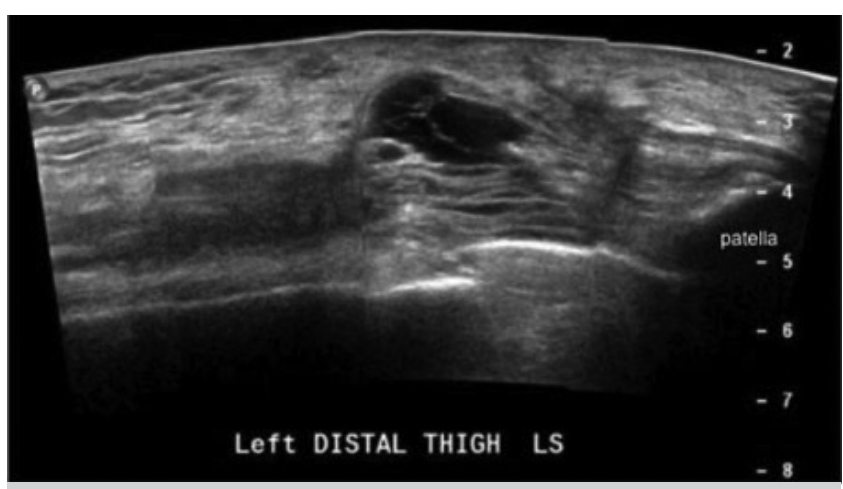

Figure-3: Ultrasound showing torn quadriceps and hematoma.

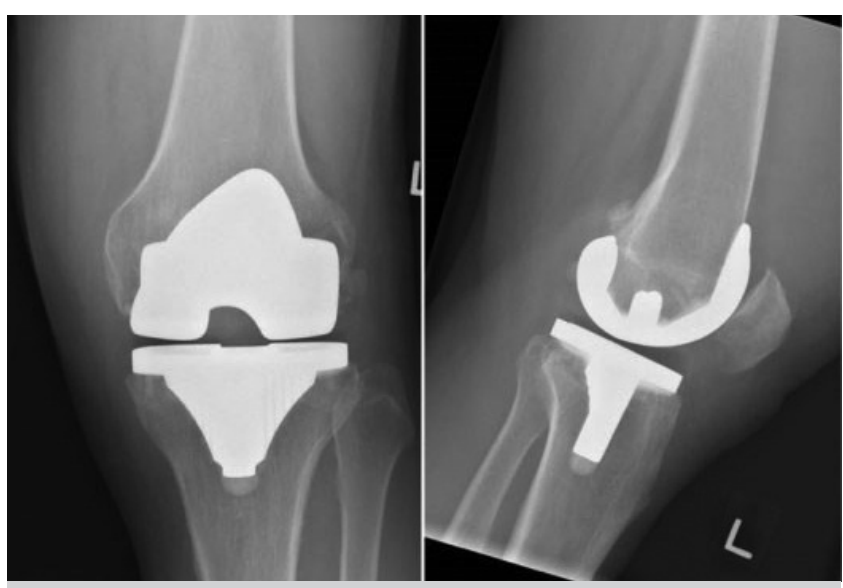

Figure-4

Case Wise functional scores are given.

There was no periprosthetic fracture as observed 


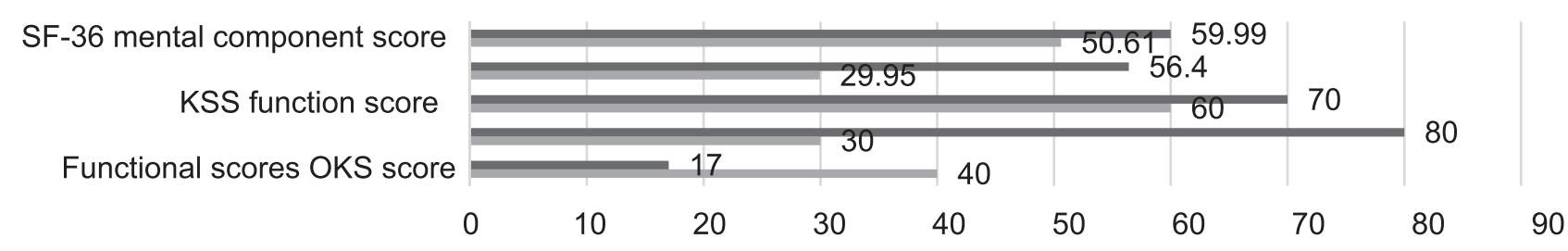

2 Years Postoperative $\square$ Preoperative

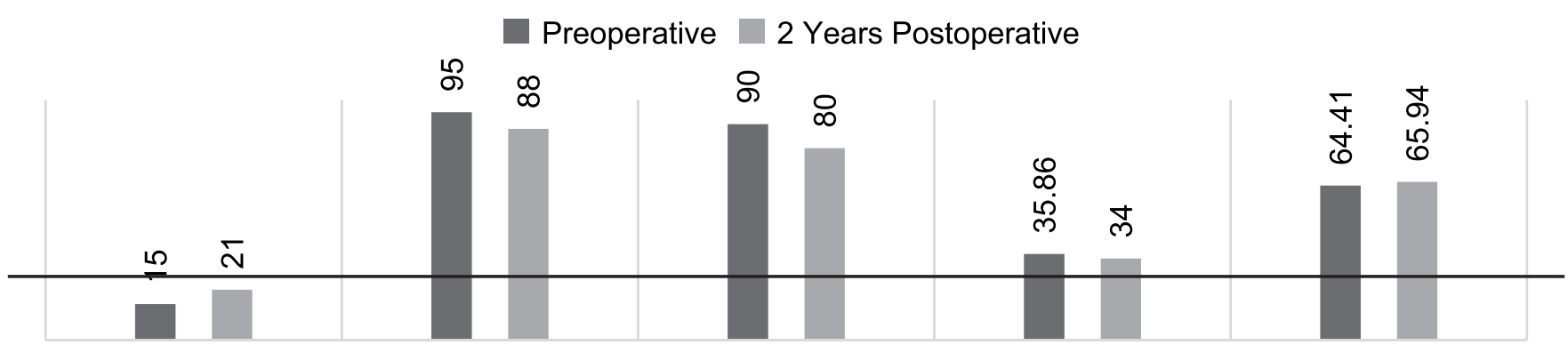

OKS

KSS KNEE SCORE
KSS FUNCTION SF-36 PHYSICAL SF-36 MENTAL SCORE COMPONENT COMPONENT SCORE
SCORE CLINICAL OUTCOME

SF-36 mental component score

KSS function score

Functional scores OKS score

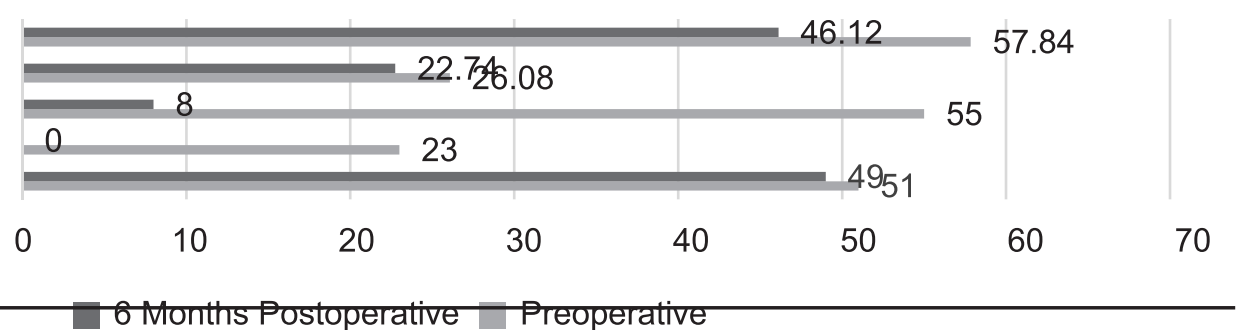

SF-36 mental component score

KSS function score

Functional scores OKS score

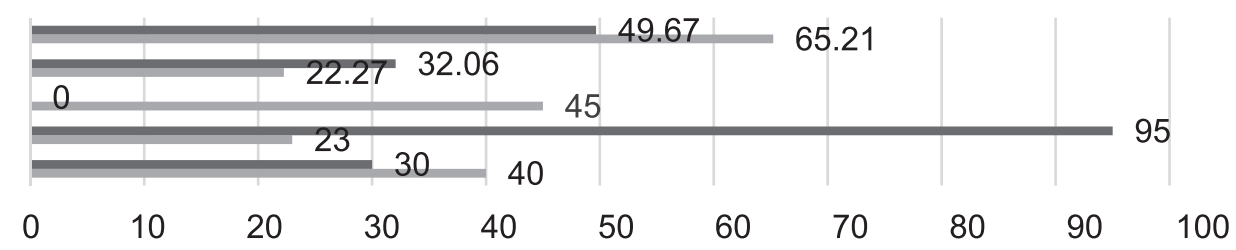

2 Years Postoperative-Preoperative

Figure-6: Shows pre-operative and post-operative scores of 4 cases from I to IV.

\section{DISCUSSION}

QTR (Quadriceps Tendon Rupture) occurs rarely after TKA (Total Knee Arthroplasty) but is a severe complication which has an association with morbidity and adverse outcomes. In this research, poor outcomes were reported among three out of four patients after quadriceps tendon rupture repair. Literature shows that the chances of success of primary extensor mechanism repair after TKA are very low. ${ }^{8-11}$

Schoderbek reported complications of disruption of extensor mechanism in his series with an overall degraded functional outcome. ${ }^{11}$ Poor 
outcomes were found directly in those patients who underwent partial quadriceps rupture suture repair. The problems were not found in the initial stage as the three patients received conservative treatment. Patient with better functional outcomes had complete quadriceps tendon tear and he received transosseous repair along with anchoring of the sutures. Kim also utilized the similar method and reported suitable outcomes. ${ }^{15}$

Literature identifies various risk factors correlated with extensor mechanism disruptions which are either surgeon related or patients related. The patient related factors include previous infection of the knee, prior knee procedures, trauma, prior alignment procedures of extensor mechanism, comorbidities such as obesity, diabetes mellitus, systemic lupus erythematosus, rheumatoid arthritis and chronic renal failure..$^{10,11,16-21} \mathrm{We}$ reported diabetes mellitus, chronic renal failure and obesity among two patients. Surgeon related factors are surgical approach and prosthetic design. ${ }^{11,20,22-24}$ Insufficient exposure also leads to increased strain to extensor mechanism in the course of retracting, patella over resection. Incision into quadriceps tendon which is a step of medial parapatellar approach may bear healing of quadriceps tendon and rupture risk. Lateral incision to musculotendinous interval may cause partial disruption of quadriceps tendon integrity insertion to patella proximal pole which may contribute to postoperative quadriceps rupture.

Patients also showed unsuitable outcomes and delayed diagnosis in this series. Even in case of postoperative pain and weakness complaints the extensor mechanism was intact. No extensor lag and defect of palpable tissue were reported in the examination. Mizner also reported worse motion range of knee on performance assessment after experiencing TKA at one-month followup. ${ }^{25}$ Ultrasound is suggested in case of trauma postoperatively to detect extensor weakness which can help in better and timely diagnosis in order to prevent delayed quadriceps tendon repair. Timely tendon repair is recommended in the literature to avoid soft tissue retraction. ${ }^{26-28}$ Poor clinical outcomes directly refer to delayed repair and diagnosis.

\section{CONCLUSION}

QTR occurs rarely after TKA but is a severe complication which has an association with morbidity and adverse outcomes. Such complications need proper handling to avoid such occurrences. Its risk can be reduced by timely diagnosis which is important for better clinical outcomes. Ultrasonographic assessment is very much helpful for exclusion of fractures and quadriceps tendon rupture.

\section{CLINICAL MESSAGE:}

It is important to screen QTR with ultrasonographic assessment post-surgery.

Copyright 02 Oct, 2019.

\section{REFERENCES}

1. Park SS, Kubiak EN, Wasserman B, et al. Management of extensor mechanism disruptions occurring after total knee arthroplasty. Am J Orthop (Belle Mead NJ) 2005; 34(8):365-372.

2. Suarez JC, Al-Mansoori AA, Kanwar S, et al. Effectiveness of novel adjuncts in pain management following total knee arthroplasty: a randomized clinical trial. The Journal of arthroplasty. 2018; 33(7):S136-41.

3. Khan M, Osman K, Green G, Haddad FS. The epidemiology of failure in total knee arthroplasty: avoiding your next revision. The bone \& joint journal. 2016; 98(1_Supple_A):105-12.

4. Mizner RL, Petterson SC, and Snyder-Mackler L. Quadriceps strength and the time course of functional recovery after total knee arthroplasty. J Orthop Sports Phys Ther 2005; 35(7):424-436.

5. Hak DJ, Sanchez A, and Trobisch P. Quadriceps tendon injuries. Orthopedics 2010; 33(1): 40-46.

6. Choi YJ, Ra HJ. Patient satisfaction after total knee arthroplasty. Knee surgery \& related research. 2016; 28(1):1.

7. Morrey MC, Barlow JD, Abdel MP, Hanssen AD. Synthetic mesh augmentation of acute and subacute quadriceps tendon repair. Orthopedics. 2016; 39(1):e9-13.

8. Gustillo R and Thompson R. Quadriceps and patellar tendon ruptures following total knee arthroplasty. In: Rand JA and Dorr LD (eds) Total arthroplasty of the knee: proceedings of the Knee Society, 1985-1986. Rockville: Aspen, 1987; pp.41-47. 
9. Lynch AF, Rorabeck $\mathrm{CH}$, and Bourne RB. Extensor mechanism complications following total knee arthroplasty. J Arthroplasty 1987; 2: 135-140.

10. Yun AG, Rubash HE, Scott RD, et al. Quadriceps rupture associated with a proximal quadriceps release in total knee arthroplasty. $A$ report of three cases. J Bone Joint Surg Am2003; 85-A (9): 1809-1811.

11. Dobbs RE, Hanssen AD, Lewallen DG, et al. Quadriceps tendon rupture after total knee arthroplasty. Prevalence, complications, and outcomes. J Bone Joint Surg Am 2005; 87(1):37-45.

12. Schoderbek RJ Jr, Brown TE, Mulhall KJ, et al. Extensor mechanism disruption after total knee arthroplasty. Clin Orthop Relat Res 2006; 446: 176-185.

13. Insall J, Dorr L, Scott R, et al. Rationale of the Knee Society clinical rating system. Clin Orthop Relat Res 1989; 248:13-14.

14. Dawson J, Fitzpatrick R, Murray D, et al. Questionnaire on the perceptions of patients about total knee replacement. J Bone Joint Surg Br 1998; 80: 63-69.

15. Ware JE, Kosinski M, and Dewey JE. How to score version two of the SF-36 health survey. Lincoln: Quality Metric Incorporated, 2000.

16. Kim TW, Kamath AF, and Israelite CL. Suture anchor repair of quadriceps tendon rupture after total knee arthroplasty. J Arthroplasty 2011; 26(5): 817-820. DOI: 10.1016/j.arth.2011.01.006.

17. Busfield BT, Huffman GR, Nahai F, et al. Extended medial gastrocnemius rotational flap for treatment of chronic knee extensor mechanism deficiency in patient with and without total knee arthroplasty. Clin Orthop Relat Res 2004; 428:190-197.

18. Emerson RH Jr, Head WC, and Malinin TI. Extensor mechanism reconstruction with an allograft after total knee arthroplasty. Clin Orthop Relat Res 1994; 303: 79-85.
19. Fernandez-Baillo N, Garay EG, and Ordonez JM. Rupture of the quadriceps tendon after total knee arthroplasty. A case report. J Arthroplasty 1993; 8: 331-334.

20. Jaureguito JW, Dubios CM, Smith SR, et al. Medial gastrocnemius trans position flap for the treatment of disruption of the extensor mechanism after total knee arthroplasty. J Bone Joint Surg Am 1997; 79: 866-873.

21. Nazarian DG and Booth RE Jr. Extensor mechanism allografts in total knee arthroplasty. Clin Orthop Relat Res1999; 367: 123-129.

22. Rasul AT Jr and Fischer DA. Primary repair of quadriceps tendon rupture. Results of treatment. Clin Orthop Relat Res1993; 289: 205-207.

23. Callahan CM, Drake BG, Heck DA, et al. Patient outcomes following tricompartmental total knee replacement. A metanalysis. JAMA 1994; 271(17): 1349-1357.

24. Skou ST, Roos EM, Laursen MB, et al. A randomized, controlled trial of total knee replacement. $\mathrm{N}$ Engl J Med 2015; 373(17): 1597-1606.

25. Garvin KL, Scuderi G, and Insall JN. Evolution of the quadriceps snip. Clin Orthop 1995; 321: 131-137.

26. Scott RD and Siliski JM. The use of a modified V-Y quadriceps plasty during total knee replacement to gain exposure and improve flexion in the ankylosed knee. Orthopedics 1985; 8: 45-48.

27. Whiteside LA. Exposure in difficult total knee arthroplasty using tibial tubercle osteotomy. Clin Orthop 1995; 321:32-35.

28. Trousdale RT, Hanssen AD, Rand JA, et al. V-Y quadriceps plasty in total knee arthroplasty. Clin Orthop 1993; 286:48-55.

\begin{tabular}{|c|l|l|l|}
\hline \multicolumn{3}{|c|}{ AUTHORSHIP AND CONTRIBUTION DECLARATION } \\
\hline Sr. \# & \multicolumn{1}{|c|}{ Author(s) Full Name } & \multicolumn{1}{c|}{ Contribution to the paper } & Author(s) Signature \\
\hline 1 & M. Zaigham Maqsood & $\begin{array}{l}\text { All authors participated } \\
\text { equally in bringing the idea, } \\
\text { modifying it, data collection } \\
\text { and writing this article. }\end{array}$ \\
\hline 3 & M. Arqam Maqsood & M. Haisum Maqsood & \\
\hline
\end{tabular}

